\title{
Study on the Art Education in Yunnan Ethnic Areas
}

\author{
Jie Zhu \\ Honghe University, Music Academy, Honghe, Yunnan, 654400
}

Keywords: Yunnan, Ethnic Areas, Art Education, Analysis

\begin{abstract}
In the ethnic minority areas of Yunnan in China, with the deepening of reform and opening up and economic development, the art education has also made great progress. Based on the field research, this paper collects and summarizes the current situation of art education in ethnic minority areas in Yunnan Province and discovers some problems from the art education of ethnic minorities in Yunnan Province. It also puts forward some targeted thinking and measures in order to give some advice and suggestions. A suitable way for the long-term development of art education in Yunnan's ethnic minority areas has been found.
\end{abstract}

\section{Introduction}

Yunnan is located in the southwestern border of China with numerous ethnic groups. It is an important part of our country. Strengthening art education in ethnic minority areas of Yunnan plays an important role in further promoting the harmony among ethnic groups and ethnic harmony and further promoting the unity and progress of the Chinese nation. Art education is an inevitable requirement and an important way and an effective measure for the full implementation of quality education. The art education in ethnic minority areas of Yunnan not only cultivates and enhances the overall quality of students, but also emphasizes the development and inheritance of colorful cultures of ethnic minorities in Yunnan. Enhancing art education in ethnic minority areas of Yunnan will lay a good foundation for the long-term development of students in ethnic minority areas in Yunnan and will be extremely beneficial for enhancing the overall quality of students. This article collects the present situation of art education in ethnic minority areas of Yunnan from the field investigation, and finds out some existing problems, and puts forward some targeted thinking and measures in order to start a discussion so that everyone can find a suitable Yunnan the Way of Long-term Development of Art Education in Ethnic Minority Regions.

\section{The current situation of art education in Yunnan ethnic minority areas}

In order to accurately grasp the specific situation of art education in ethnic minority areas of Yunnan, the author made some field visits and investigations. The main research methods are to listen to the teachers in the classroom, observe the extra-curricular activities of students, exchange opinions with teachers and students, and take some forms of questionnaires. As a whole, they have mastered the ethnic minority areas in Yunnan. Overall, in recent years, with the vigorous advocacy and support of the nation on ethnic culture, artistic education in ethnic minority areas in Yunnan Province has made great strides in its development and progress. It is manifested in paying more attention to art education and its professional competence Progress has been made, students' enthusiasm for learning and motivation have improved. Especially with the vigorous implementation of quality education advocated by the state, it is a great impetus to art education in Yunnan's ethnic minority areas. Although the positive results have been achieved, there is still some problems such as the weak foundation and unbalanced development of the arts education in the ethnic minority areas in Yunnan. There is an imbalance between the economic and social development in the region and there are also many historical constraints.

In the research, I found that there is still not enough place to know art education all over the place. Mainly reflected in: First, there is no good combination of art education and culture class, there has been the phenomenon of fragmentation. Survey found that most schools pay more 
attention to the cultural class, but to some extent ignored the art education class, they have not enough understanding of the characteristics of the image training and aesthetic thinking that the art class possesses. In the teaching activity, Musical characteristics of the students, visual thinking exercise. Second, art teaching is not enough to explore, to teach more, the art of teaching as a pediatrics, see simple, to find a better combination of art education and student awareness of the lack of integration of the law to explore is not deep. The third is not enough attention, the art of teaching as a dessert, or directly equivalent to extra-curricular activities or general interest activities, but the embellishment of student activities, usually during the festival to increase the number of theatrical performances to add some atmosphere, without the art Lessons and cultural lessons equal. Fourthly, there is not enough research on art education. Unlike the schools of Chinese, math and foreign languages, the university attaches equal importance to research. Many of the activities of art classes in schools report performances and the exchange of professional education in art education is not enough.

\section{Art education problems in Yunnan ethnic minority areas}

The content of art education is different from the native culture of Yunnan. The content of art education must accord with the connotation of art aesthetic needs display. At the same time, we need to closely integrate local culture in order to obtain more long-term and stronger vitality. From the process of investigation, we found that the content of art education displayed by many teaching activities has deviated from the actual situation of Yunnan native culture to a certain extent and has not been effectively integrated with the ethnic arts and culture created by Yunnan's ethnic minorities over the long history. It can be said that the art education observed in most ethnic minority areas has nothing to do with the national folk art in Yunnan. In addition, from the perspectives of teaching activities, extracurricular cultural activities and organized theatrical performances, ethnic characteristics Not prominent and intense enough.

Art education textbooks lack local characteristics. The existing art teaching materials for primary and secondary schools have greatly improved their quality and ideology, but they are still generally out of the scope of professional arts education. Most textbooks can not meet the needs of primary and secondary students physical and mental characteristics. In terms of teaching contents, the teachers think much while the students think less; the capacity of knowledge is pursued in a comprehensive and systematic manner, while the level of students and the need to be considered are few; skills requirements also take less into account the actual needs of students in ethnic minority areas, adapting to the needs of art education, there are even fewer textbooks that contain the content of local ethnic culture and the arts. Art education in ethnic minority areas needs to be based on the actual situation, refer to the existing unified textbook, and pay more attention to giving play to the role of guidance and teaching of some optional textbooks with ethnic and local characteristics.

Aesthetic education and aesthetic excitement enough. The emphasis of art education is to educate the students on aesthetic education so that students can appreciate the beauty of nature and life in the art study. However, the aesthetic education in Yunnan ethnic minority areas has not paid enough attention to the aesthetic value. Local art teachers generally follow the traditional teaching methods in teaching. How teachers teach, how students learn and take pictures, this kind of art teaching method is difficult to realize the aesthetic in the areas of ethnic minorities with inadequate art and equipment and economic difficulties education. In the survey, we found that some remote schools and art teachers lacked the artistic quality and did not have enough teaching methods to meet the needs of aesthetic education. Art teaching should not only pay attention to the general education law and teaching principle, but also can not be completely equivalent to the general culture teaching. Art teaching is the teaching of beauty. It is a touch-based teaching of the mind. It can not simply copy and copy the teaching of the culture course, but only focuses on the points of knowledge. More attention should be paid to the students' feelings on the beauty and the aesthetic awareness.

Art teacher shortage of resources. In the survey, the state (city) education committees and schools reflected that the lack of teachers is an important factor restricting the education of ethnic art in all localities. These schools urgently need to further supplement and upgrade the art teachers' 
resources. Lack of teachers' resources, many of them due to the lag of history and economic development, have caused many art graduates to be unwilling to come to these regions. The art teachers who come to these areas usually have too poor working and living conditions, poor job titles, and the teachers do not want to stay for a long time. Others feel that they are going to a good place for teaching in urban areas, and some are unsure of teaching.

These problems appear for many reasons, of which the most important ones are not enough attention and inadequate investment by the competent departments in all localities, but also the weakness of the art teachers in ethnic minority areas in Yunnan Province, the lack of training capacity in art education teachers and the higher and higher vocational education in arts Set too narrow, training objectives and artistic needs of ethnic minority areas are still out of line. One reality is that the slogan of quality education shouts loudly. However, when it comes to actual implementation, exam-oriented education is still the dominant factor. Art education management and research work has not been effectively included in the school leadership's important work schedule. Art education is often neglected. There is not enough education for quality education. There is no common understanding and unification to better meet the artistic needs of Yunnan ethnic minority areas and make better use of local cultural resources to carry out arts education.

\section{The improvement of art education in ethnic areas as an effective way to think}

In response to the above problems, in order to effectively meet the needs of quality education, effectively solve the problems existing in art education and improve the quality of art education, the author proposes the following solutions and measures.

Pay attention to avoid weaknesses, give full play to local art features. Art education in ethnic minority areas of Yunnan should pay full attention to making full use of the local resources advantages of local ethnic arts and using the most regional and local art resources to effectively solve the problems of weak local cultural foundation and backward educational facilities. We should pay attention to the inheritance and development of folk art in all ethnic groups and make compilation of local art teaching materials. In particular, we should pay attention to improving the contents of textbooks related to art education in normal schools. Art or vocational institutions should focus on the art of Yunnan ethnic minority courses. In this regard, the Nujia Teachers' Classroom Exercise adapted from the basic movements of the Lisu folk dances to gain the love of many students for their innovative integration with ethnic dances. The Dehong Longchuan National Primary School in classroom teaching and extra-curricular activities, focusing on teaching folk art embroidery, wood carving bamboo, paper-cut, clay to achieve better results, access to all levels of leadership and parents praise.

To strengthen training, establish an effective system of training system. To strengthen the training of art education teachers, in particular, to strengthen the training of local primary and secondary school principals, increase education and management of art education, comprehensively improve the policy of primary and secondary school administrators in ethnic minority areas, so that they can better understand The management of arts education will enable them to pay more attention to the arts and culture of the local ethnic groups so as to further stimulate and enhance their sense of mission and responsibility toward the development of arts education in ethnic minority areas. At the same time, to actively organize art training, part-time art teachers can have the opportunity to participate, this is tantamount to opening up another avenue, not just art colleges and universities. This kind of training to enhance part-time artistic teachers ability to art quality can effectively alleviate the shortage of art teachers in Yunnan minority areas.

Art colleges and universities in ethnic minority areas should strengthen the cultivation of land art talents in light of the actual situation. It is necessary to establish an art education system featuring ethnic minorities in Yunnan. Colleges and universities of higher learning should pay attention to cultivating qualified teachers who are willing to engage in ethnic and folk arts education and take it as an important task. We must take active measures so that more ethnic minority students can learn, learn and learn well. We should focus on enriching the teaching content, in particular, increasing the training of folk arts and culture knowledge and skills of Yunnan's main ethnic groups. The trained 
talents of art education not only love national folk art, cherish strong national emotion, rich artistic knowledge and artistic skills.

Strengthen the treatment of art teachers to protect. Educational departments and schools at all levels should treat art teachers equally regardless of their job title, and attach great importance to improving the status of music and art teachers in schools so that they can give full play to their strengths and be effectively protected. This is also the goal of implementing quality education Demonstration of requirements.

Authorities should pay attention to strengthening arts education. Relevant education authorities should take the initiative to give full play to their functions, strengthen the centralized demonstration and demonstration of the teaching achievements in arts education, summarize the advanced experience of promoting arts education activities, and make schools at all levels learn from each other and work together to enhance them. In particular, the provincial education commission should give full play to its functions and responsibilities. Special funds for art education in ethnic minority areas should be delineated, teaching tools should be earmarked for the purchase of art education, and infrastructure conditions for art education in various regions should be delineated. Ethnic primary and secondary schools to buy paper, color and other consumer equipment. Provincial Education Commission of art education for the purchase of teaching materials should also promptly allocated all over the configuration of the equipment must meet the needs of all places.

\section{Conclusions}

Under the current development situation, to further strengthen the art education in Yunnan's ethnic minority areas, it is necessary to recognize the rich and colorful cultural resources of ethnic minorities in Yunnan and realize that there are still many tasks for making full use of these cultural resources do. At the same time, it is necessary to recognize the great demand for art education in ethnic minority areas in Yunnan, as well as the weak infrastructure of arts education and infrastructure in Yunnan's ethnic minority areas. This requires a clear understanding of the important role of art education for ethnic minorities in Yunnan. In order to better integrate the regional and ethnic characteristics of ethnic minority art resources in Yunnan and the needs of art education in ethnic minority areas in Yunnan, we should actively create innovation and make efforts to promote the ethnic minorities in Yunnan Art education personnel training ability, so that the arts education in Yunnan fully embodies the local characteristics of local ethnic minority areas in Yunnan.

On the basis of in-depth investigation and research, this paper mainly describes the status quo of art education in ethnic minority areas of Yunnan and points out the shortcomings and problems of art education in Yunnan's minority nationality areas. On the basis of analyzing the status quo and problems, this paper puts forward some countermeasures and suggestions to improve and strengthen art education in ethnic minority areas in Yunnan Province. It mainly aims to arouse the attention of Education Commission and education administrative departments, implement the requirements of quality education in an all-round way, pay more attention to and explore Yunnan Local ethnic traits, combined with the needs of students, the introduction and training, training excellent ability of art education professional teachers, improve the art teacher training system, is bound to Yunnan ethnic minority area art education has played a significant role in promoting and promoting.

\section{References}

[1] Li Jiji, Liu Suying. Ethnic folk artists and primary and secondary education in ethnic minority areas of art [J]. National Arts, 2000 (S1)

[2] Sheng Ru-fen. Predicament and Outlet of Comprehensive Art Education in Elementary and Middle Schools in Frontier Minority Areas - A Survey Based on Yao'an County, Yunnan Province [J]. China Out-of-School Education, 2012 (07) 
[3] Li Tong, Sheng Yong-hong Status Quo and Countermeasures of Education Level of Rural Families in Ethnic Minority Areas of Yunnan Province - A Sample Survey and Analysis Report on Educational Burden Rates in Yunnan Minority Areas [J]. Journal of Economic Research, 2008 (08)

[4] He Lianglin, paragraph Peng. Analysis of Education in Frontier Minority Areas - A Case Study of Jinping, Miao and Yao Autonomous County in Yunnan Province [J]. Journal of Fuling Teachers College, 2007 (03)

[5] Zhao Yawei Consideration on the Inheritance of Local Music Culture in College Music Education in Yunnan Minority Areas - A Case Study of Music Education Major of Lijiang Teachers College [J]. Science \& Technology Information, 2012 (02) 